\title{
Budaya komunikasi virtual di Twitter dan Tiktok: Perluasan makna kata estetik
}

\author{
Marisa Oktavianaa ${ }^{\mathrm{a}, 1}$, Zainal Abidin Achmad ${ }^{\mathrm{b}, 2^{*}}$, Heidy Arviani ${ }^{\mathrm{c}, 3}$, Kusnarto $^{\mathrm{d}, 4}$ \\ abcd Universitas Pembangunan Nasional Veteran Jawa Timur, Jalan Raya Rungkut Madya Gunung Anyar, \\ Surabaya, 60294, Indonesia \\ ${ }^{1}$ mrsoktavia99@gmail.com; ${ }^{2}$ z.abidinachmad@upnjatim.ac.id; ${ }^{3}$ heidy_arviani.ilkom@upnjatim.ac.id; \\ ${ }^{4}$ kusnarto.ilkom@upnjatim.ac.id \\ *Corresponding Author
}

\begin{tabular}{l}
\hline INFO ARTIKEL \\
\hline Sejarah Artikel: \\
Diterima: 28 Juli 2021 \\
Direvisi: 2 September 2021 \\
Disetujui: 16 September 2021 \\
Tersedia Daring: 31 Oktober \\
2021 \\
\hline
\end{tabular}

Budaya Komunikasi Virtual Etnografi Virtual

Kata Estetik

Makna Kata

Media Sosial \begin{abstract}
ABSTRAK
Kata estetik mengalami perluasan makna dari makna asalnya akibat penggunaannya di Twitter dan TikTok. Perluasan makna itu menimbulkan perdebatan pada pengguna kedua media sosial tersebut. Studi ini bertujuan untuk mengetahui penyebab dan proses terjadinya perluasan makna, termasuk motivasi pengguna Twitter dan TikTok menggunakan kata estetik yang maknanya berbeda dengan Kamus Besar Bahasa Indonesia (KBBI). Studi berjenis kualitatif ini menggunakan pendekatan etnografi virtual dengan mewawancarai tujuh informan pengguna Twitter dan TikTok. Empat orang informan pengguna Twitter, yaitu @iyayaudahgpp, @semanismimpimu, @s8joh, dan @CharmingDevilll. Tiga orang informan pengguna TikTok, yaitu @Wiyantika, @aqua.ush, dan @pcynjm131. Hasil penelusuran virtual menunjukkan bahwa kata estetik telah mengalami perluasan makna. Kata estetik tidak sekadar bermakna indah tetapi juga berarti ungkapan kelucuan, ekspresi sindiran, dan pujian penampilan fisik. Penyebab perluasan makna adalah penggunaan kata estetik pada caption, cuitan, komentar, dan tagar oleh pengguna Twitter dan TikTok. Motivasi penggunaan kata estetik, disebabkan mengikuti tren, keisengan, dan candaan. Budaya berkomunikasi di media sosial berperan penting dalam perluasan makna kata dan penciptaan kata-kata baru.
\end{abstract}

Keywords:

Aesthetics Word

Social Media

Virtual Communication

Cultures

Virtual Ethnography

Word Meaning

\section{ABSTRACT}

The word aesthetic has expanded from its original meaning due to its use on Twitter and TikTok. The expansion of meaning has caused debate among users of the two social media. This study aims to determine the causes and processes of the expansion of meaning, including Twitter and TikTok users' motivation to use aesthetic words that have different meanings from the Indonesian Dictionary (KBBI). The type of research is qualitative with a virtual ethnographic approach by interviewing seven informants using Twitter and TikTok. Four Twitter user informants, namely@iyayaudahgpp, @semanismimpimu, @s8joh, and @CharmingDevilll. Three informants using TikTok, namely @Wiyantika, @aqua.ush, and @pcynjm131. The virtual search results show that the word aesthetic has expanded its meaning. The word aesthetic does not only mean beautiful but also means an expression of cuteness, an expression of satire, and a compliment of physical appearance. The cause of the expansion of meaning is the use of aesthetic words in captions, tweets, comments, and hashtags by Twitter and TikTok users. The motivation for using the word aesthetic is due to following trends, fads, and jokes. The culture of communicating on social media has an essential role in expanding the meaning of words and creating new words. 


\section{Pendahuluan}

Akhir-akhir ini, dua media sosial yaitu Twitter dan TikTok menunjukkan masifnya penggunaan kata estetik yang tidak sesuai dengan makna asalnya. Kata estetik digunakan secara bervariasi pada berbagai unggahan konten di Twitter dan TikTok. Kata estetik bukanlah kata baku dalam Kamus Besar Bahasa Indonesia. Kata bakunya adalah "estetika", sebuah kata benda yang merujuk kepekaan terhadap seni dan keindahan. Kata sifatnya adalah "estetis" yang artinya mempunyai penilaian terhadap keindahan (KBBI V, 2020).

Budaya komunikasi virtual di media sosial menyebabkan kata-kata yang sebelumnya telah dikenal luas atau populer, mengalami perubahan semantik, pragmatis, gaya, dan tata bahasa (Kilyeni, 2015). Sosial media memberikan keuntungan dalam peningkatan kemampuan menulis dan berbahasa seseorang. Salah satunya adalah penciptaan kata dan makna baru (Tenore, 2013). Jika pada media sosial terdapat sebuah kata cukup persuasif, dengan penggunaan yang provokatif, meluas dan nyata, dapat dikatakan sebuah kata memiliki makna baru (McKean, 2009). Hal ini terjadi sebagaimana munculnya kata estetik yang memiliki kesalahan eja dari kata yang telah populer sebelumnya yaitu "estetika".

Menurut data Twitter, Indonesia adalah salah satu dari lima negara terbesar pengguna aktif Twitter karena terdapat 78 juta akun pengguna aktif Twitter di Indonesia (Salim \& Mayary, 2020). Sedangkan jumlah akun TikTok aktif di Indonesia mencapai 30,7 juta pengguna (Pebrianto \& Setiawan, 2021), menjadikan Indonesia sebagai negara pengunduh aplikasi TikTok terbanyak di dunia (Ferdiansyah, 2020), berjumlah 11 persen dari 63,3 juta pungunduh aplikasi TikTok di dunia (Ramadhan, 2020).

Twitter merupakan aplikasi jejaring sosial yang memberikan layanan komunikasi untuk menghubungkan teman, keluarga, maupun sesama penggunanya. Keterhubungan para pengguna Twitter didukung oleh fitur layanan microblogging, yang memungkinkan pengguna untuk mengunggah pesan singkat yang dibatasi maksimal 140 karakter, baik dalam bentuk teks, foto, video, maupun audio (Hadna, Santosa, \& Winarno, 2016). TikTok adalah aplikasi jejaring sosial dengan platform video dan musik, sehingga memungkinkan pengguna untuk mengunggah berbagai konten yang berisikan nyanyian, tarian, dan tutorial (Aji \& Setiyadi, 2020).

Media sosial baru membuat proses komunikasi berjalan lebih cepat dan mudah (Sari, 2018). Dari proses-proses komunikasi yang dilakukan oleh setiap individu tersebut akan mempengaruhi dan dipengaruhi oleh individu yang lainnya dalam konteks pertukaran makna pada lambang-lambang simbolik (Pernandi, 2018). Tak terkecuali pemaknaan sebuah kata dalam media sosial Twitter dan TikTok.

Dari proses pertukaran makna yang terjadi di Twitter dan TikTok ini, pada akhirnya menghasilkan suatu pergeseran makna pada kata estetik yang telah meluas dari makna asalnya. Perluasan makna tersebut merupakan suatu fenomena yang menunjukkan bahwa bahasa itu berkembang selaras dengan pengetahuan dan kebutuhan pemakainya. Perluasan makna dapat terjadi karena beberapa faktor, yaitu faktor kebutuhan kata baru, faktor sosial masyarakat, dan faktor perbedaan tanggapan pemakai bahasa (Nurhidayati, 2017). 
Media sosial adalah media baru yang muncul sebagai arus utama dalam proses pertukaran informasi dan interaksi di seluruh dunia (Suratnoaji, Arianto, \& Sumardjijati, 2018). Keberadaan media sosial di dunia virtual telah melahirkan budaya komunikasi virtual (Achmad, Arviani, \& Santoso, 2021; Alamiyah, Arviani, \& Achmad, 2021; Andayani \& Achmad, 2020; Arviani \& Febrianita, 2020; Castells, 2008). Media sosial sebagai media baru untuk berkomunikasi, yang populer antara lain, Facebook, Instagram, Twitter dan TikTok (Candrasari, 2019).

Terkait peran media sosial dalam penciptaan kata dan pemaknaan baru pada kata estetik, TikTok dan Twitter menjadi media yang tepat dalam kemunculannya. Bahwa pada perkembangan budaya virtual, media sosial dengan platform unggahan seketika seperti TikTok dan Twitter, turut memiliki andil penting dalam membuat sesuatu yang berbeda. Estetik bukan hanya sekadar kata, tetapi perpaduan ranah teknologi dan mediatics. Kata estetik menjadi sangat populer ketika diunggah pada media yang memberikan peluang yang sesuai dengan wacana estetis. TikTok dan Twitter menyediakan lahirnya perluasan makna estetik karena penggunanya memiliki pemikiran kritis mengenai ekspresi budaya, teknologi indera, dan pengalaman dalam kehidupan sehari-hari (Hausken, 2020).

Makna dari suatu kata memang dapat berubah dari makna leksikalnya. Makna dalam sebuah kata, secara diakronis dapat mengalami perubahan, tetapi secara sinkronis tidak. Artinya, dalam kurun waktu yang singkat, suatu makna dalam suatu kata akan tetap sama, namun dalam kurun waktu yang lama terdapat kemungkinan makna dalam suatu kata tersebut bisa berubah (Fatmawati, Andianto, \& Husniah, 2014). Dalam perubahan dan pergeseran makna, rujukan awal dari suatu kata tidak diganti atau mengalami perubahan, tetapi mengalami penyempitan atau perluasan makna (Rahma, Nuzula, Safitri, \& Hs, $\underline{2018) .}$.
Proses pemaknaan suatu kata dapat ditentukan apabila kata tersebut telah berada dan digunakan pada satu runtutan bahasa (Damayanti, 2019). Hal ini berarti bahwa suatu kata tidak dapat berdiri sendiri, melainkan suatu kata akan memiliki maknanya jika kata tersebut berada di dalam runtutan bahasa. Bahkan, suatu kata juga dapat berbeda artinya apabila disandingkan dengan runtutan bahasa yang berbeda pula. Begitu juga kata estetik yang digunakan dalam setiap konten unggahan di media sosial Twitter dan TikTok.

Fenomena massifnya penggunaan kata estetik secara langsung terkait dengan estetika sosial. Unggahan konten seseorang di media sosial, merupakan ekspresi perasaan, pendapat dan pikiran pengguna atau pemilik akun. Tagar \#estetik muncul tidak mungkin jika tidak memiliki hubungan dengan perasaan atau pendapat seseorang yang menyinggung tentang keindahan. Ketika terjadi interaksi antara pengguna Twitter dan TikTok dalam menggunakan kata estetik di konten unggahan mereka. Secara tidak disengaja, para pengguna media sosial membuat makna sendiri tentang estetik. Estetik yang dimaknai Bersamasama adalah estetika sosial (Coleman, 2014).

Untuk itulah studi ini bertujuan untuk penggunaan kata estetik di Twitter dan TikTok, (2) penggunaan kata estetik di berbagai jenis unggahan konten dan cuitan, (3) menemukan makna baru dari kata estetik, (4) motivasi pengguna Twitter dan TikTok untuk menggunakan kata estetik dalam unggahan konten dan cuitan. Selain itu untuk mendukung hasil beberapa penelitian terdahulu tentang kemampuan budaya komunikasi virtual di media sosial dalam menciptakan kata baru dan makna kata baru.

Beberapa penelitian terdahulu memiliki relevansi dengan studi ini, antara lain temuan bahwa media sosial Line memberikan dukungan pada munculnya makna baru "hijrah" bagi komunitaskomunitas virtual Let's Hijrah. Secara bersama-sama, seluruh anggota komunitas 
melakukan konstruksi makna hijrah sebagai pembentuk identitas komunitas virtual tersebut (Prasanti \& Indriani, 2019).

Penelitian berikutnya mengungkap motivasi para pengguna Instagram ketika melakukan unggahan Meme pada akun Instagram mereka. Hasilnya menunjukkan bahwa motivasi pengguna Instagram adalah (1) untuk memberikan informasi aktivitas pemilik akun kepada followers mereka atau lebih dikenal sebagai tindakan Want To Pamer atau WTP (istilah populer para netizen), (1) untuk mendapatkan pengalaman baru membuat Meme, (3) untuk mendapatkan perhatian dari followers berupa like dan comment (Nugraha, 2015).

Penelitian lain yang secara spesifik meneliti makna penataan unggahan foto-foto makanan di Instagram (Foodstagram) secara estetis dapat mengkonstruksi definisi nikmat bagi para pengguna Instagram (Arumsari \& Agung, 2019). Pemanfataan unsur estetika (pencahayaan, tata letak, dan komposisi warna) dalam unggahan foodstagram mampu menarik pengguna Instagram dan memberikan definisi baru dari frasa "kenikmatan". Kenikmatan makanan tidak sekadar didefinisikan dari mencicipinya, tetapi bisa diperoleh dari penglihatan mata terhadap foto-foto makanan di Instagram.

\section{Metode}

Penelitian berjenis kualitatif ini menggunakan pendekatan etnografi virtual. Etnografi virtual sebagai suatu metode yang berupaya untuk menggali lebih dalam mengenai subjek atau fenomena yang terjadi di dunia virtual atau ruang virtual (Achmad, 2020; Achmad \& Ida, 2018; Hine, 2000, 2004). Ruang virtual sebagai tempat hidup komunitas-komunitas virtual menjadi sarana komunikasi interaktif yang dipahami sebagai budaya virtual ataupun artefak budaya (Achmad, Ida, Mustain, \& LukensBull, 2021; Achmad, Juwito, Candrasari, \& Ashfaq, 2021; Achmad, Juwito, \& Saud, 2020).

Etnografi virtual ini tidak hanya sebatas penelitian pada tentang budaya, tetapi bertujuan untuk merekam pergerakan pada perilaku masyarakat dengan menggabungkan teknik observasi (pengamatan) dan teknik wawancara. Selain itu, beberapa kesepakatan pada prosedur metode etnografi virtual adalah fokus penelitian berpusat pada komunikasi yang berlandaskan pada teks dan mengambil catatan lapangan secara rinci. Para peneliti tetap harus berlaku sebagai partisipan yang melakukaan aktivitas bersama para subjek di dunia nyata dan dunia virtual (Achmad \& Ida, 2018; Angelone, 2018; Hine, 2015; Markham, 1998).

Para peneliti dalam studi ini melakukan pengumpulan data melalui (1) wawancara virtual para informan dengan Direct Message di Twitter dan Tiktok, (2) pengamatan dan penelusuran virtual terhadap aktivitas yang dilakukan oleh pengguna keyword estetik di Twitter dan tagar \#estetik di TikTok, berupa posting-an konten, cuitan, dan komentar. Agar hasil pencarian pada data-data virtual dapat didokumentasikan dan dilacak kembali, peneliti menggunakan aplikasi pearltrees untuk menyimpan data-data penelusuran tersebut.

Penentuan informan dalam studi ini berdasarkan kategori sebagai pemilik akun aktif di Twitter dan TikTok dan pengguna keyword estetik dan tagar \#estetik di Twitter dan TikTok. Informan dari Twitter, yaitu: (1) https://twitter.com/iyayaudahgpp (2) https://twitter.com/semanismimpimu https://twitter.com/CharmingDevilll https://twitter.com/s8joh. Informan dari TikTok: (1) https://tiktok.com/@Wiyantika (2) https://www.tiktok.com/@aqua.ush (3) https://www.tiktok.com/@pcynjm131.

Para peneliti menggunakan dua akun Twitter, https://twitter.com/toppingnutella dan https://twitter.com/AbidinZachro serta menggunakan dua akun TikTok https://www.tiktok.com/@mrsoktvn dan https://www.tiktok.com/@zabman08 milik para peneliti. Penggunaan akun media sosial para peneliti menjadi sarana untuk berlaku sebagai partisipan di dunia virtual bersama para informan. 
Unit analisis pada penelitian ini adalah teks, berupa huruf dan kata, simbol, foto, dan video pada unggahan konten Twitter dan TikTok. Seluruh teks hasil penelusuran kemudian dianalisis dengan metode padan, yaitu analisis bahasa dengan alat penentu yang berasal dari luar bahasa atau terlepas dari bagian bahasa itu sendiri. Analisis padan ada dua jenis, padan referensial dan padan pragmatis (Sudaryanto, 1993).

Kategori informasi yang diteliti, yaitu proses perluasan makna estetik, bentukbentuk penggunaan kata estetik dalam Twitter dan TikTok, penyebab terjadinya perluasan makna kata estetik, dan motivasi pengguna Twitter dan TikTok menggunakan kata estetik. Kategorisasi berdasarkan pemilahan temuan konten di TikTok dan cuitan di Twitter.

\section{Hasil dan Pembahasan}

Berdasarkan hasil penelusuran virtual di Twitter dan TikTok, awal mula kemunculan tagar \#estetik berbahasa Indonesia di Twitter adalah pada tanggal 17 Desember 2010 (Twitter, 2021). Kata estetik tidak hanya digunakan sebagai bentuk apresiasi pada karya seni saja, tetapi juga digunakan untuk konten media sosial Twitter dan TikTok. Hal ini kemudian menyebabkan perdebatan bagi sebagian khalayak karena merasa penggunaan kata estetik tersebut tidak sesuai dengan kaidah yang seharusnya (Saputra, 2021).

Sebagaimana ulasan dalam artikel di majalah HAI online (gambar 1) yang mengungkap perdebatan penggunaan kata estetik, sekaligus meluruskan makna kata estetik sesuai pengertian dalam bahasa Inggris "aesthetic". Pemaknaan kata estetik di media sosial digunakan untuk mengungkapkan dan memuji suatu gaya atau vibe tertentu. Singkatnya, pemaknaan kata estetik di media sosial memiliki arti "keren banget!" (Saputra, 2021).

Meskipun kata estetik ini mengalami perdebatan oleh khalayak, tetapi masih banyak digunakan untuk konten media sosial Twitter dan TikTok. Hingga saat ini penggunaan kata estetik di Twitter mencapai

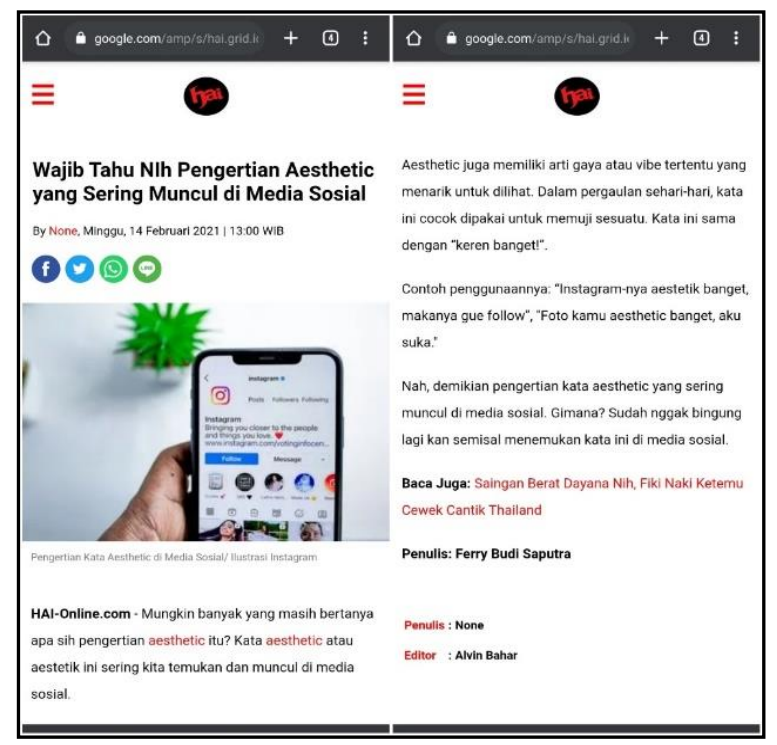

Gambar 1. Artikel populer di majalah HAI Online yang mengulas makna kata estetik

sekitar 590 cuitan per tanggal 27 Juni 2021 (Twitter, 2021) dan di TikTok sebanyak 730,6 milyar unggahan konten video dengan tagar \#estetik dengan berbagai bahasa, hingga bulan Juli 2021 (TikTok, 2021).

Makna kata estetik mulai mengalami pergeseran sejak adanya penggunaan kata estetik di Twitter dan TikTok di akhir tahun 2020, pada unggahan konten yang ternyata maknanya berbeda dari KBBI. Bukti pergeseran makna tersebut dapat dibandingkan penggunaan kata estetik di internet pada beberapa artikel ilmiah. Artikel ilmiah dipilih karena menjelaskan makna kata estetik yang sebenarnya.

Kata estetik dalam artikel ilmiah digunakan untuk menilai keindahan dari suatu karya seni, baik itu kerajinan, tata letak, maupun rincian dari rumah tradisional (gambar 2).

Selanjutnya dibandingkan dengan penggunaan kata estetik di berbagai konten unggahan di media sosial Twitter dan Tiktok dengan cara yang berbeda pada akhir tahun 2020. Penggunaan kata estetik di kedua media sosial tersebut tidak lagi digunakan untuk mengungkapkan keindahan dari seni saja, melainkan juga digunakan untuk cuitan mereka di berbagai postingan twitter (gambar 3) dan postingan konten berupa video dan musik di Tiktok (gambar 4). 
Penggunaan kata estetik yang berbeda antara artikel ilmiah dan unggahan di media



Gambar 2. Penggunaan kata estetik di berbagai artikel ilmiah sosial, menjadi bukti bahwa kata estetik telah mengalami perluasan makna.
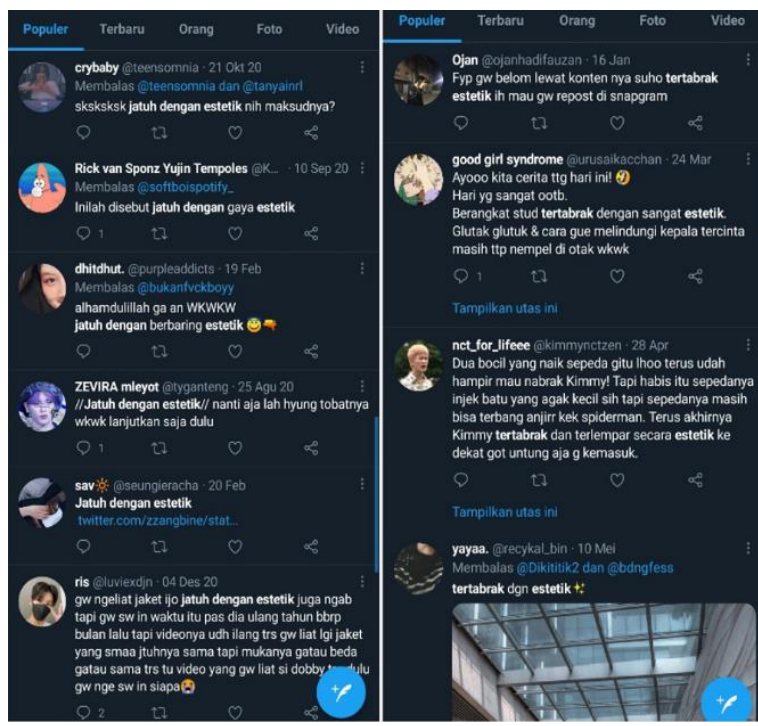

Gambar 3. Penggunaan kata estetik di Twitter

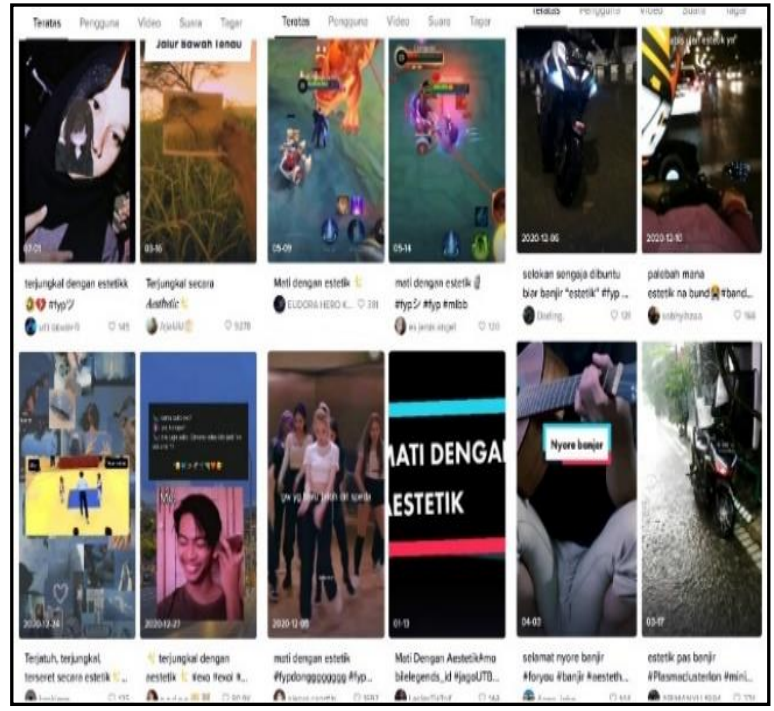

Gambar 4. Penggunaan kata estetik di TikTok

Penggunaan kata estetik yang berbeda antara artikel ilmiah dan unggahan di media sosial, menjadi bukti bahwa kata estetik telah mengalami perluasan makna. Temuan bahwa kata estetik telah mengalami perluasan makna diakui oleh pengguna Twitter dan TikTok. Mereka menyatakan bahwa cuitan di Twitter dan unggahan konten di Tiktok digunakan untuk mengungkapkan sesuatu hal yang dianggap lucu, unik, kenyamanan, dan keren. Termasuk memberikan komentar pada postingan tertentu yang muncul di Twitter dan TikTok (wawancara @iyayaudahgpp dan @ semanismimpimu, 2 Juni 2021).

Penggunaan kata-kata di media sosial tidak perlu mengikuti aturan atau kaidah yang baku. Pengguna media sosial justru mendapatkan kebebasan berekspresi dengan kata dan kalimat yang mereka inginkan. Sahsah saja bagi pengguna media sosial memilih kata dan memberi makna sesuai kehendak mereka. Setiap orang memiliki kebebasan hak untuk menggunakan kata estetik dengan makna apapun untuk mengekpresikan 
perasaan apapun (wawancara @s8joh dan @Wiyantika, 7 Juni 2021).

Banyak pengguna Twitter dan TikTok yang tidak sadar dan tidak paham makna sebenarnya dari kata estetik. Karena itulah mereka bebas untuk memberikan makna pada kata estetik. Beberapa makna baru dari estetik tersebut antara lain: kenyamanan (gambar 5), kenikmatan (gambar 6), kelucuan (gambar 7), kekonyolan (gambar 8), keren (gambar 9).

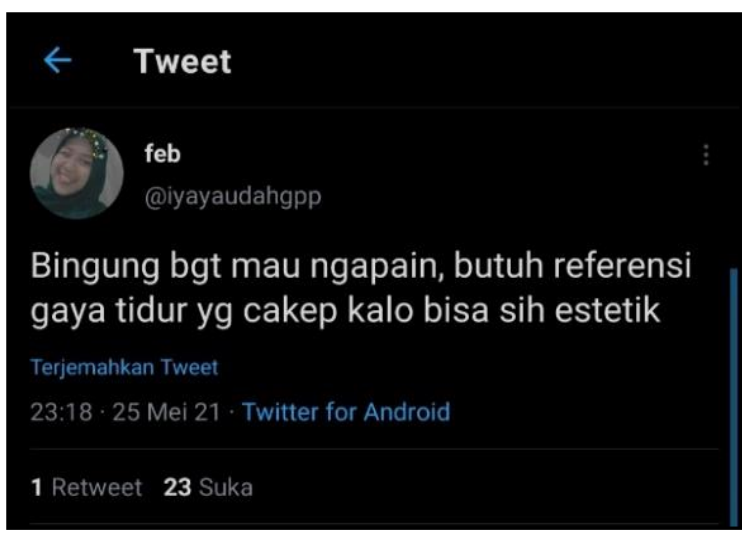

Gambar 5. Kata estetik bermakna kenyamanan (cuitan berharap tidur nyenyak dan nyaman).

Perluasan makna baru "kenyamanan" pada kata estetik (gambar 5), secara analisis padan termasuk padan referensial karena merujuk pada perasaan dan harapan @yayaudahgpp untuk memperoleh kenyamanan apabila melakukan kegiatan tidur. Sebagaimana diakui oleh @ yayaudahppp bahwa cuitan tersebut adalah ungkapan perasaan dan harapannya setelah melakukan kegiatan yang melelahkan dan membutuhkan istirahat yang nyaman (wawancara @yayaudahppp, 2 Juni 2021).

Perluasan makna baru "kenikmatan" dari kata estetik (gambar 6), termasuk padan referensial. Makna tersebut merujuk pada kondisi yang dihadapi @CharmingDevilll ketika makan dengan menu kesukaannya yaitu pete dan sambal. Secara spontan saja @CharmingDevilll mengakui bahwa makan pete pedas merupakan kenikmatan rasa yang sulit dijelaskan dengan kata-kata (wawancara @CharmingDevilll, 4 Juni 2021).

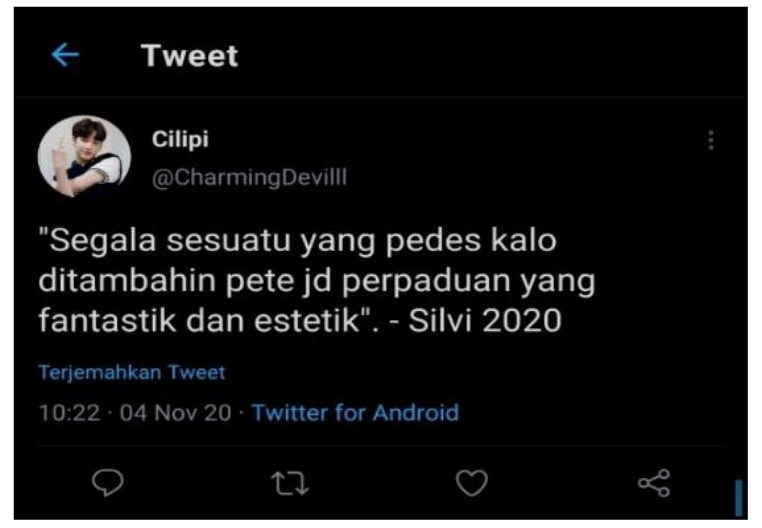

Gambar 6. Kata estetik bermakna kenikmatan (cuitan perpaduan makanan yang nikmat).

Makna "kelucuan" yang ditunjukkan oleh unggahan@Wiyantika pada gambar 7 termasuk padan pragmatis. Pemberian makna yang dilakukan oleh @Wiyantika dan pengguna media sosial lain karena kata estetik memiliki kesesuaian dengan adegan lucu pada sebuah film.

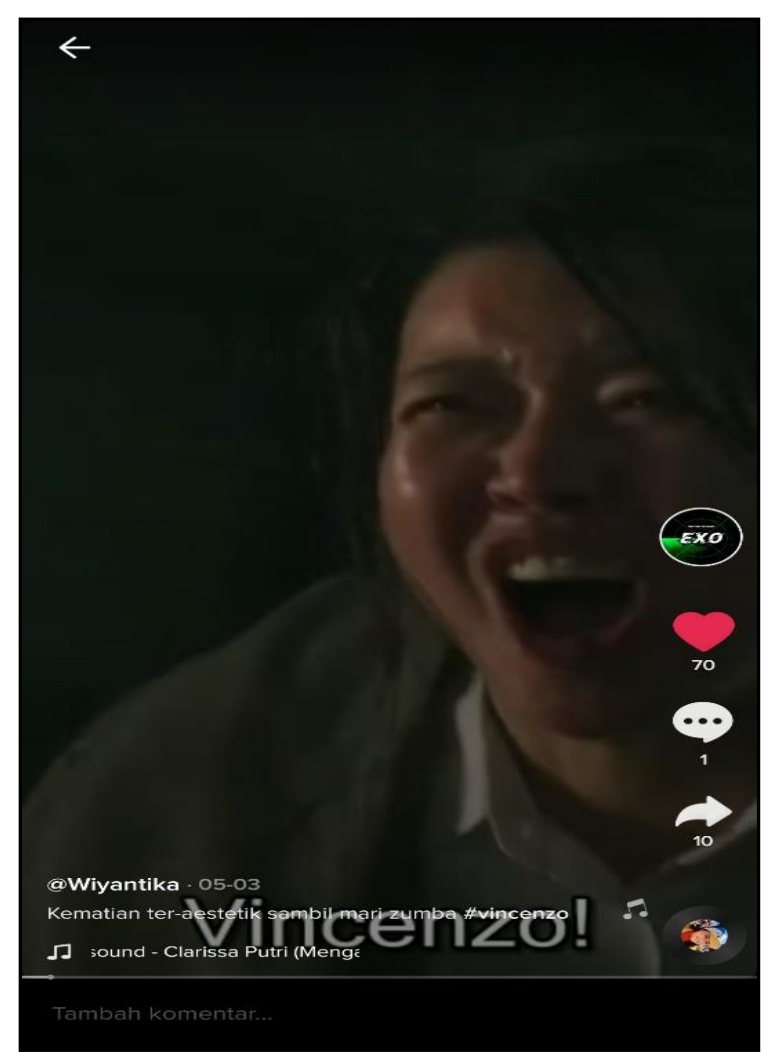

Gambar 7. Kata estetik bermakna kelucuan (konten tiktok adegan pembunuhan dalam sebuah film tetapi musik latarnya senam zumba) 
Unggahan tersebut adalah potongan scene sebuah film dengan adegan pembunuhan, namun terdapaat kejanggalan pada adegen tersebut, yaitu penggunaan musik latar yang berirama rancak seperti iringan senam Zumba. Wujud kegemasan pada unggahan lucu tersebut, @Wiyantika mewakilinya dengan kata estetik (wawancara@Witanyika, 7 Juni 2021).



Gambar 8. Kata estetik bermakna kekonyolan (konten tiktok adegan jatuh dengan posisi unik)

Makna baru "kekonyolan" muncul dari para pengguna TikTok yang mengunggah konten yang menurut mereka adalah tindakan yang tidak masuk akal atau sembrono (gambar 8). Makna baru kekonyolan termasuk padan referensial, yang merujuk pada unggahan konten berupa perilaku atau tindakan sembrono akibat pelaku tidak berpikir panjang. Kata estetik dipilih oleh@aqua.ush ketika menunjukkan contoh unggahan konten dari akun @funwithyou tentang seorang remaja bermain skateboard yang terjatuh karena melakukan manuver secara sembrono (wawancara @ aqua.ush, 4 Juni 2021).

Makna "keren" yang muncul dari kata estetik adalah padan pragmatis (gambar 9). Maka tersebut merujuk pada perkembangan

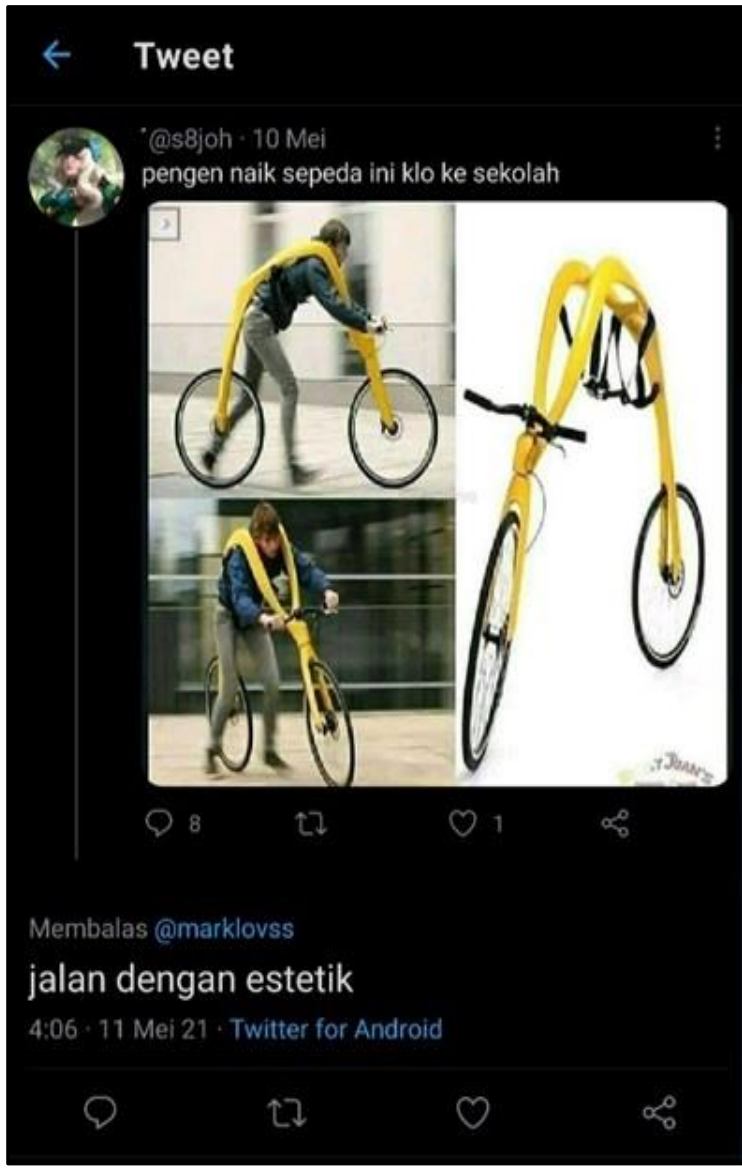

Gambar 9. Kata estetik bermakna keren (cuitan dengan gambar teknologi baru sepeda)

teknologi sepeda yang menurut @s8joh sangat inovatif. Perpaduan antara olahraga, kreativitas dan kecanggihan menurut @ s8joh secara pragmatis dapat diwakili oleh makna "keren" (wawancara@s8joh,7 Juni 2021)

Penyebab dari bergesernya makna kata estetik di media sosial Twitter dan Tiktok ini adalah karena mereka tidak mengetahui makna kata estetik sebelumnya. Dan saat mereka melihat berbagai konten unggahan di media sosial tersebut, kata estetik dinilai dapat mewakili berbagai perasaan dan peristiwa. Kata estetik tidak sekadar merujuk pada benda tetapi juga sifat atau keadaan (wawancara @Wiyantika dan @ pcynjm131, 15 Juni 2021).

Hasil penelusuran virtual dari akun para informan, mereka lebih banyak menilai bahwa kata estetik menjadi ekspresi perasaan hati yang sedang bergembira atau suka. Hal ini terlihat dari konten dan cuitan yang tidak mengandung unsur perasaan 
marah atau jengkel. Cuitan di Twitter dan unggahan konten video musik mereka menimbulkan reaksi tersenyum dan tertawa bagi yang membaca atau melihatnya.

Penelusuran terhadap motivasi para pengguna Twitter dan TikTok dalam menggunakan kata estetik, sebagian besar karena didasari alasan mengikuti tren yang sedang berlangsung terhadap penggunaan kata estetik. Sebagian beralasan karena sekadar iseng tanpa tahu makna kata estetik. Menariknya, pada pengguna Twitter dan TikTok yang mengetahui makna kata estetik justru menggunakannya untuk bahan bercanda terhadap arti kata keindahan (wawancara @CharmingDevilll dan @aqua.ush, 8 Juni 2021). Bahkan para pengguna Twitter dan TikTok tidak memiliki tendensi khusus untuk untuk menaikkan engagement. Tidak ada motivasi untuk menambah kenaikan followers (wawancara@Wiyantika dan @ pcynjm131, 10 Juni 2021).

Konfirmasi terhadap umur para pengguna kata estetik di Twitter dan TikTok menunjukkan bahwa mereka termasuk kategori generasi Z, yaitu generasi yang lahir setelah tahun 1995 (Cilliers, 2017). Penyebutan generasi $\mathrm{Z}$ karena generasi ini memiliki tahun kelahiran pada 1990-an dan dibesarkan pada tahun 2000-an, ketika dunia mengalami perubahan paling besar dalam sejarah umat manusia dengan hadirnya internet, website, laptop, telepon seluler, media digital, dan jaringan yang tersedia secara bebas (Singh \& Dangmei, 2016). Sebuah generasi yang menjalani masa muda dan dewasanya pada masa ekonomi dan sosial terkini, serta memiliki kehidupan pada dua dunia (nyata dan virtual). Kehidupan mereka pada dua dunia tersebut tidak tersekat dan dapat dijalani secara bersamaan. Dunia virtual adalah pelengkap kehidupan mereka di dunia nyata (Dolot, 2018).

Konsekuensi dari memiliki kehidupan dua dunia, menjadikan Generasi $\mathrm{Z}$ mudah mendapatkan informasi yang dibutuhkan dan dapat melakukan konfirmasi informasi dengan segera. Mereka juga memiliki kecepatan untuk saling berbagi informasi dengan banyak orang. Pemrosesan komunikasi di antara generasi $\mathrm{Z}$ berlangsung secara berkelanjutan, karena mereka menggunakan berbagai macam perangkat komunikasi dan media sosial (Zis, Effendi, \& Roem, 2021). Generasi Z adalah pengguna media sosial yang aktif, memiliki banyak kontak, menjalani hubungan kehidupan sehari-hari melalui media sosial, dan menilai pertemuan pribadi secara daring memiliki peran penting dalam kehidupan sosial mereka (White, 2017).

Perilaku generasi $\mathrm{Z}$ dalam berkomunikasi di Twitter dan TikTok yang berperan dalam perluasan makna kata estetik, dapat diamati berdasarkan teori perubahan makna dan semantik kognitif dalam kajian kebahasaan. Fenomena perubahan makna kata dalam bahasa Indonesia dapat dijelaskan berdasarkan dimensi sejarah dan dimensi sosial (Nurhidayati, 2017). Apabila dilihat dari alasan pengguna Twitter dan TikTok untuk menggunakan kata estetik karena untuk mewakili kelucuan, kekonyolan, dan perasaan gembira, menunjukkan bahwa perluasan makna terjadi karena ada motivasi kognitif para pengguna Tiktok dan Twitter. Alasan mengikuti tren di media sosial, menunjukkan bahwa perluasan maka kata estetik karena ada jejaring semantik yang berlangsung di Twitter dan TikTok.

Secara etimologi, perubahan makna pada kosakata Bahasa Indonesia yang paling banyak terjadi adalah perluasan makna (Mita, 2020). Penyebabnya ditentukan oleh pengalaman dan pengetahuan pemakai Bahasa. Sebagaimana yang terjadi pada kata estetik, pengalaman dan pengetahuan pengguna Twitter dan TikTok yang berbedabeda dalam memahami kata estetik, sehingga maknanya menjadi meluas. Tidak jarang setiap perubahan makna kosakata bahasa Indonesia masih memiliki keterkaitan dengan makna asalnya tetapi dapat dirangkai dalam jejaring semantik yang terjadi di berbagai media sosial.

Perluasan makna kata dalam bahasa Indonesia yang terjadi di tengah kehidupan sosial masyarakat, di antaranya faktor 
historis, faktor sosial, faktor psikologis, faktor perkembangan ilmu dan teknologi, faktor perbedaaan tanggapan pemakai bahasa, faktor kebutuhan kata baru dan faktor pengaruh bahasa asing (Nurhidayati, 2017). Faktor terpenting yang menyebabkan perluasan makna kata estetik yang terjadi di tengah pengguna Twitter dan TikTok dipengaruhi oleh perkembangan ilmu dan teknologi, perbedaan tanggapan oleh pemakai bahasa dalam bidang pemakaian, dan perkembangan hubungan sosial masyarakat.

Perkembangan ilmu pengetahuan dan teknologi utamanya adalah teknologi komunikasi yang melahirkan internet, web dan media sosial, yang memberikan kemampuan kepada banyak orang untuk dapat berkomunikasi di dalam jaringan tanpa dibatasi jarak, waktu, dan wilayah (Castells, 2004; Lowisz, 2017). Perkembangan teknologi komunikasi (internet dan media sosial) berdampak pada perubahan hubungan sosial antara manusia dan terjadi berbagai pergeseran budaya. Budaya berkomunikasi tatap muka berubah menjadi budaya berkomunikasi virtual (Achmad, Arviani, et al., 2021; Donath, 1999; Soffani \& Nugroho, 2019; Utami, Lestari, \& Putra, 2015). Perubahan budaya berkomunikasi berdampak pada perkembangan kebahasaan dengan terciptanya berbagai kata dan makna baru (Rahma et al., 2018).

Penyebab lain dari perluasan makna kata estetik adalah bidang pemakaian yaitu sebagai ekspresi berbagai perasaan, kondisi, dan rujukan. Perasaan yang diwakili oleh kata estetik adalah gembira dan suka. Kondisi yang diwakili kata estetik adalah kelucuan dan kekonyolan. Rujukan yang diwakili kata estetik adalah kenyamanan dan kenikmatan. Faktor bidang pemakaian bahasa adalah proses bagaimana pengguna bahasa memberi makna pada kata estetik sesuai dengan objek yang dideskripsikan (Hamilton, Leskovec, \& Jurafsky, 2016). Karena sebuah kata adalah komponen bahasa yang memuat keseluruhan informasi tentang makna sekaligus pemakaian kata dalam bahasa berdasarkan objek yang dideskripsikannya (Mita, 2020).

Faktor penyebab berikutnya adalah perkembangan sosial budaya. Perluasan makna kata estetik dikaitkan latar belakang sosial budaya penggunanya. Sebagaimana penjelasan tentang kategori umur pengguna Twitter dan TikTok yang Sebagian besar berasal dari generasi Z. Sebuah generasi yang sangat aktif dan produktif menggunakan media sosial dalam berkomunikasi dan berinteraksi secara sosial. Perpaduan antara generasi $\mathrm{Z}$ dan media sosial, menyediakan sarana ekspresi kreativitas dalam unggahan berbagai konten dan pesan di TikTok dan Twitter baik berupa video, foto, musik, dan grafis $($ Sandel \& Ju, 2019).

Para pengguna Twitter dan TikTok yang dominan berasal dari generasi $\mathrm{Z}$ mendapatkan kebebasan untuk memilih dan menentukan makna yang sesuai dari sebuah kata. Mereka cenderung memilih makna yang memiliki relevansi dengan makna asalnya. Begitulah pengguna Twitter dan TikTok melakukan bentuk penghargaan dan penghormatan pada kata estetik, dengan memberikan makna yang untuk mendeskripsikan benda dan keadaan.

\section{Kesimpulan}

Perluasan makna kata estetik di Twitter dan TikTok bermula pada akhir tahun 2020, ketika banyak akun yang menggunakan kata estetik sebagai cuitan dan unggahan konten. Beberapa makna baru dari kata estetik yang diciptakan oleh para pengguna Twitter dan TikTok, antara lain kenyamanan, kenikmatan, kelucuan, kekonyolan, dan keren.

Penyebab perluasan makna pada kata estetik ini adalah sebagian besar pengguna Twitter dan TikTok tidak mengetahui makna asli dari kata estetik sesuai KBBI. Pengguna media sosial menilai sah-sah saja untul menempatkan kata estetik sesuai kehendak mereka, asalkan mewakili perasaan hati yang sedang bergembira.

Motivasi para pengguna Twitter dan Tiktok dalam menggunakan kata estetik, 
antara lain, karena mengikuti tren, iseng semata, bercanda dengan makna keindahan, dan tidak untuk meningkatkan engagement unggahan dan tidak untuk menaikkan jumlah pengikut.

Menurut perspektif kebahasaan, proses perluasan makna kata estetik disebabkan oleh tiga faktor, yaitu perkembangan teknologi komunikasi, perbedaan tanggapan pengguna bahasa sesuai bidang pemakaian, dan perkembangan hubungan sosial masyarakat.

Studi tentang perluasan makna kata estetik di Twitter dan TikTok ini mendukung berbagai penelitian yang menyatakan bahwa media sosial berperan penting dalam penciptaan kata-kata baru dan makna-makna baru.

\section{Ucapan Terima Kasih}

Para peneliti menyampaikan ucapan terimakasih kepada: Himpunan Pembina Bahasa Indonesia (HPBI) Provinsi Jawa Timur, Asosiasi Dosen Bahasa dan Sastra Indonesia (ADOBSI) Jawa Timur, dan reviewer Jurnal Satwika.

\section{Daftar Pustaka}

Achmad, Z. A. (2020). Pergeseran relasi antara pendengar radio dengan institusi radio dalam masyarakat jaringan (Studi etnografi virtual pada radio-radio budaya di Jawa Timur yang Bermediamorfosis). Universitas Airlangga.

Achmad, Z. A., Arviani, H., \& Santoso, N. R. (2021). The Sanak-Kadang Jodhipati: A new form of virtual radio listeners Community. Jurnal ASPIKOM, 6(1), 94-109. doi:10.24329/aspikom.v6i1.830

Achmad, Z. A., \& Ida, R. (2018). Etnografi virtual sebagai teknik pengumpulan data dan metode penelitian. The Journal of Society \& Media, 2(2), 130 145. doi:10.26740/jsm.v2n2.p130-145

Achmad, Z. A., Ida, R., Mustain, M., \& Lukens-Bull, R. (2021). The synergy of Islamic Da'wah and Madura culture programmes on Nada FM Sumenep
Radio, Indonesia. Jurnal Komunikasi: Malaysian Journal of Communication, 37(2), 111-129. doi:https://ejournal.ukm.my/mjc/article /view/37323/12023

Achmad, Z. A., Juwito, J., Candrasari, Y., \& Ashfaq, A. (2021). Advantages of implementing mediamorphosis in supporting using-ethnic programs at Radio Sritanjung FM Banyuwangi. Masyarakat, Kebudayaan Dan Politik, 34(2), 133-146. doi:http://dx.doi.org/10.20473/mkp.V3 4I22021.133-146

Achmad, Z. A., Juwito, J., \& Saud, M. (2020). The local creative ads on Sritanjung FM to increase financial revenue during Covid-19 pandemic. Bricolage: Jurnal Magister Ilmu Komunikasi, 6(2), 135-146. doi:10.30813/bricolage.v6i02.2229

Aji, W. N., \& Setiyadi, D. B. P. (2020). Aplikasi Tik Tok sebagai media pembelajaran keterampilan bersastra. Metafora, 6(2), 147-157, http://dx.doi.org/10.30595/mtf.v6i1.78 24

Alamiyah, S. S., Arviani, H., \& Achmad, Z. A. (2021). Mothers' medical-based experience as the most sought-after online information by new mothers during pandemic Covid-19. The Journal of Society and Media, 5(1), 7898. doi:10.26740/jsm.v5n1.p78-98

Andayani, T. J., \& Achmad, Z. A. (2020). Parenting with Rumah Keluarga Risman: Facebook group as information society and determinant of technology function. Indonesian Journal of Social Sciences, 12(02), 6272 ,

http://dx.doi.org/10.20473/ijss.v12i2.2 2909

Angelone, L. (2018). Virtual ethnography: The post possibilities of not being there. Mid-Western Educational Researcher, 31(3), 275-295, 
http://www.mwera.org/MWER/volume s/v31/issue3/V31n3-Angelone-

DISTINGUISHED-PAPER.pdf.

Arumsari, R. Y., \& Agung, L. (2019). Constructing deliciousness through Instagram: The aesthetics of foodstagram. 6 Th Bandung Creative Movement International Conference in Creative Industries 2019, 2019, 2-6, https://media.neliti.com/media/publicat ions/293365-constructing-

deliciousness-through-insta-

c17f85dd.pdf.

Arviani, H., \& Febrianita, R. (2020). Ehealth communication on Instagram posts: Contents analysis of Alodokter. Metacommunication: Journal of Communication Studies, 5(1), 1-12, http://dx.doi.org/10.20527/mc.v5i1.80 19

Candrasari, Y. (2019). Mediated interpersonal communication: A new way of social interaction in the digital age. In Proceedings of the 2nd International Media Conference 2019 (IMC 2019) (pp. 537-548). Paris, France: Atlantis Press. doi:10.2991/assehr.k.200325.041

Castells, M. (2004). Informationalism, networks, and the network society: A theoretical blueprint. In M. Castells (Ed.), The network society: a crosscultural perspective (p. 488). Northampton: Edward Elgar. https://doi.org/10.4337/978184542166 3

Castells, M. (2008). Materials for an exploratory theory of the network society. British Journal of Sociology, 51(1), $5-24$ doi:10.1080/000713100358408

Cilliers, E. J. (2017). The Challenge of teaching generation Z. PEOPLE: International Journal of Social Sciences, 3(1), 188-198. doi:10.20319/pijss.2017.31.188198

Coleman, E. B. (2014). Defining 'Social
Aesthetics'. Defining 'Social Aesthetics', 23(1), 1-16, https://www.researchgate.net/publicati on/323956438_Defining_Social_Aesth etics.

Damayanti, R. (2019). Analisis makna kata pada kemasan permen relaxa, Jurnal Bahasa dan Sastra, 4(4), 92-102, http://jurnal.untad.ac.id/jurnal/index.ph $\mathrm{p} / \mathrm{BDS} /$ article/view/12206

Dolot, A. (2018). The Characteristics of Generation Z. E-Mentor, 2(74), 44-50. doi:10.15219/em74.1351

Donath, J. S. (1999). Identity and deception in the virtual community. In M. A. Smith \& P. Kollock (Eds.), Communities in Cyberspace (pp. 2959). Routledge.

Fatmawati, Andianto, M. R., \& Husniah, F. (2014). Kata-kata berubah makna dalam wacana opini di surat kabar Jawa Pos edisi Januari 2014. Artikel Ilmiah Mahasiswa, (1), 1-9. Retrieved from http://repository.unej.ac.id/handle/123 456789/63204

Ferdiansyah, M. (2020). Jumlah unduhan Tiktok kalahkan Facebook dan Instagram.

https://techno.okezone.com/read/2020/ 01/16/207/2153835/jumlah-unduhantiktok-kalahkan-facebook-daninstagram

Hadna, M. S., Santosa, P. I., \& Winarno, W. W. (2016). Studi literatur tentang perbandingan metode untuk proses analisis sentimen di Twitter. Seminar Nasional Teknologi Informasi Dan Komunikasi, 2016(Sentika), 57-64, https://fti.uajy.ac.id/sentika/publikasi/ makalah/2016/95.pdf

Hamilton, W. L., Leskovec, J., \& Jurafsky, D. (2016). Cultural shift or linguistic drift? Comparing two computational measures of semantic change. EMNLP 2016 - Conference on Empirical Methods in Natural Language Processing, Proceedings, 2116-2121. 
doi:10.18653/v1/d16-1229

Hausken, L. (2020). Media aesthetics. Retrieved 26 June 2021, from https://www.hf.uio.no/imk/english/rese arch/groups/media-aesthetics/

Hine, C. (2000). Virtual ethnography. Sage Publications Ltd.

Hine, C. (2004). Virtual ethnography revisited. Online Reearch Methods, Research Methods Festival. Oxford.

Hine, C. (2015). Ethnography for the internet: Embedded, embodied, and everyday. Bloomsbury.

KBBI V. (2020). Hasil pencarian arti kata estetika. Retrieved 19 May 2021, from https://kbbi.kemdikbud.go.id/entri/este tika

Kilyeni, A. (2015). Likes, tweets and other "Friends": Social media Buzzwords from a terminology perspective. Procedia - Social and Behavioral Sciences, 192(2015), 430-437. doi:10.1016/j.sbspro.2015.06.059

Lowisz, S. (2017). The Influence of Social Media in Today's Culture. Educating Professionls, $1-12$, https://ppjp.ulm.ac.id/journal/index.ph $\mathrm{p} / \mathrm{MC} /$ article/view/8019

Markham, A. N. (1998). Life online: Researching real experience in virtual space. Alta Mira Press

McKean, E. (2009). Redefining definition. Retrieved 22 June 2021, from https://www.nytimes.com/2009/12/20/ magazine/20FOB-onlanguage-t.html

Mita, R. (2020). Pergeseran makna kosakata bahasa Indonesia pada pengguna Instagram. Universitas Muhammadiyah Makassar

Nugraha, A, (2015). Fenomena meme di media sosial: Studi etnografi virtual posting meme pada pengguna media sosial Instagram. Jurnal Sosioteknologi, 14(3), 237-245. https://doi.org/10.5614/sostek.itbj.2015
.14 .3 .3

Nurhidayati, S. A. (2017). Perubahan makna kosakata bahasa Indonesia. Universitas Sumatera Utara. Retrieved from http://repositori.usu.ac.id/bitstream/han dle/123456789/19414/147009031.pdf? sequence $=1 \&$ isAllowed $=\mathrm{y}$

Pebrianto, F., \& Setiawan, K. (2021). Harapan Sandiaga Uno untuk 30,7 juta pengguna TikTok di Indonesia. https://bisnis.tempo.co/read/1428311/h arapan-sandiaga-uno-untuk-307-jutapengguna-tiktok-di-indonesia

Pernandi, I. (2018). Studi kajian interaksionisme simbolik pondok pesantren Misbahulkhoir Bojong Purwakarta. MENDIDIK: Jurnal Kajian Pendidikan Dan Pengajaran, 4(1), $\quad 1-10$. doi:10.30653/003.201841.36

Prasanti, D., \& Indriani, S. S. (2019). Konstruksi makna hijrah bagi anggota komunitas Let'S Hijrah dalam media sosial Line. Al-Izzah: Jurnal HasilHasil Penelitian, 14(1), 106. doi:10.31332/ai.v14i1.1253

Rahma, F. A., Nuzula, N. A., Safitri, V., \& Hs, S. (2018). Pergeseran makna: Analisis peyorasi dan ameliorasi dalam konteks kalimat. Hasta Wiyata, 1(2), 111.

doi:10.21776/ub.hastawiyata.2018.001 .02 .01

Ramadhan, B. (2020). Data Internet di Indonesia dan Perilakunya Tahun 2020. https://teknoia.com/data-internet-diindonesia-dan-perilakunya880c7bc7cd19?gi=b52934a64642

Salim, S. S., \& Mayary, J. (2020). Analisis Sentimen pengguna Twitter terhadap dompet elektronik dengan metode lexicon based dan k-nearest neighbor. Jurnal Ilmiah Informatika Komputer, 25(1), $1-17$. doi:10.35760/ik.2020.v25i1.2411

Sandel, T. L., \& Ju, B. (2019). Social media, culture, and communication. In J. 
Nussbaum (Ed.), Oxford Research Encyclopedia of Communication (pp. 1-26). New York and Oxford: Oxford University

Press. doi:10.1093/acrefore/9780190228613. 013.758

Saputra, F. B. (2021). Wajib tahu nih pengertian aesthetic yang sering muncul di media sosial. https://hai.grid.id/read/072556486/waji b-tahu-nih-pengertian-aesthetic-yangsering-muncul-di-media-sosial

Sari, A. C. (2018). Komunikasi dan media sosial. Universitas Muslim Indonesia

Singh, A. P., \& Dangmei, J. (2016). Understanding the generation $\mathrm{Z}$ : The future workforce. South -Asian Journal of Multidisciplinary Studies, 3(3), 1-5, https://www.researchgate.net/publicati on/305280948_UNDERSTANDING_ THE_GENERATION_Z_THE_FUTU RE_WORKFORCE

Soffani, A., \& Nugroho, C. (2019). Unsur budaya dalam media sosial: Studi Pada Facebook Kang Dedi Mulyadi. Jurnal Manajemen Komunikasi, 3(2), 158. doi:10.24198/jmk.v3i2.12936

Sudaryanto. (1993). Metode dan aneka teknik analisis bahasa. Duta Wacana University Press

Suratnoaji, C., Arianto, I. D., \& Sumardjijati. (2018). Strength map of presidential candidates 2019 in Indonesia based on a nodeXL analysis of big data from twitter. Asian Journal for Public Opinion Research, 6(1), 31-38. doi:10.15206/ajpor.2018.6.1.31
Tenore, M. J. (2013). 5 ways that social media benefits writing and language Poynter. Retrieved 19 June 2021, from https://www.poynter.org/reportingediting/2013/5-ways-that-socialmedia-benefits-writing-the-englishlanguage/

TikTok. (2021). Video Tagar \#estetik di TikTok. Retrieved 15 July 2021, from https://vt.tiktok.com/ZSJ2bPpp7/

Twitter. (2021). estetik - Twitter Search. Retrieved 12 July 2021, from https://twitter.com/search?q=estetik\&s $=08$

Utami, A. M. V., Lestari, M. T., \& Putra, A. (2015). Pergeseran budaya komunikasi pada era media baru (Studi etnografi virtual penggunaan line oleh digital natives). In e-Proceeding of Management (Vol. 2, pp. 4042-4050). Telkom University

White, J. E. (2017). Meet Generation Z: understanding and reaching the new post-Christian world. Baker Books.

Zis, S. F., Effendi, N., \& Roem, E. R. (2021). Perubahan perilaku komunikasi generasi milenial dan generasi $\mathrm{z}$ di era digital. Satwika: Kajian Ilmu Budaya Dan Perubahan Sosial, 5(1), 69-87. doi:10.22219/satwika.v5i1.15550 